\title{
COMPLEX MODEL BASED ON UAV TECHNOLOGY FOR INVESTIGATING PASTORAL SPACE
}

\author{
M. Simon ${ }^{1}$, C.A. Popescu ${ }^{1}$, Loredana Copăcean ${ }^{1 *}$, Luminiţa Cojocariu ${ }^{1,2}$ \\ ${ }^{1}$ Banat's University of Agricultural Sciences and Veterinary Medicine „King Mihai I of \\ Romania" from Timişoara, \\ ${ }^{2}$ Agricultural Research and Development Station Lovrin, Romania. \\ *Corresponding author: lorecopacean@yahoo.com
}

Keywords: UAV, 3D point cloud, GIS, pastoral space, complex model

\begin{abstract}
Data from the specialized literature show that in the last decade there has been a rapid development in the use of unmanned aerial vehicles (UAV) for obtaining spatial information from the pastoral environment. The idea of investigating grassland surfaces with the help of drones was based on the following practical considerations: the size and complexity of pastoral space and the need for data acquisition in hard-to-reach areas and in a short time. In this context, the purpose of the research is to integrate UAV technology and GIS applications into pratological research, the results obtained having both practical and methodological character. For the efficient research of the pastoral space with UAV equipment, a working model was developed, complex from a technical point of view, consisting of several stages: identifying the areas of interest, planning and setting the flight parameters, "photographing" the area, downloading and image processing, and then processing the results in the GIS environment. From each stage, geospatial products can be extracted, and the final products can be used in various ways, both in the pastoral space and in other segments of the geographical environment. Following the application of the working algorithm results the orthophotoplan and the point clouds, from which can be extracted topo-cadastral information (related to the "physical" surface of grasslands), pratological information (related to vegetation and mode of use) or useful information in territorial planning (risk phenomena, relief aspects), with high precision and spatial location. Compared with the classical research methods, the use of the working model based on geomatic technologies, has the effect of reducing the working time and the number of operators, the possibility of tracking time and space of the investigated territory, but also the formation of graphic and descriptive databases that they can be used in other subsequent projects.
\end{abstract}

\section{INTRODUCTION}

Due to its size and complexity, the pastoral space is one of the components of the environment in which the UAV equipment and the related GIS techniques have 
brought an extra in terms of: investigating the grassland surfaces (Simon et al, 2018); vegetation analysis (Cohen et al, 2018; Sona et al, 2016); biodiversity (Sun et al, 2018; Cojocariu et al, 2018); evaluation and prediction (Sanches et al, 2018; Kyriacos, 2017), etc.

The increased interest in the field of unmanned aerial vehicles (UAV) by the scientific research community, software developers, and those with experience in the field of geomatics has in recent years determined the use of these systems in the most varied models and forms, in different fields of engineering and architecture (Ezequiel et al, 2014). This is due to their flexibility of use, as well as reduced costs compared to traditional photogrammetric flights, which use expensive metric digital cameras or LiDAR sensors (Samad et al, 2013).

UAV systems are nowadays a valuable source of data for 3D mapping, surveillance, inspection and modeling (Remondino et al, 2011). Since drones can be considered as a low-cost alternative to classical aerial photogrammetry, new applications have been introduced in the short and near field. UAV systems are capable of capturing photogrammetric data with digital cameras, they can fly either in manual, semi-automatic or automatic modes.

The measurements by the UAV technology are made in a non-invasive manner, the drones leaving no traces or emissions of any kind, during or after the measurements. The measurements are made in a short period of time and with a high temporal resolution.

Following a typical photogrammetric workflow, 3D results can be produced such as: digital surface or terrain models, contours, textured 3D models, vector information, etc., on small and medium surfaces (Casian et al, 2019).

A UAV system can be used to study pastoral space, when national regulation permits, for various applications. These images have a very high resolution if the flights are made at a height of 100-120 m above the ground (Simon et al, 2018). Very large overlays of $70-75 \%$ are recommended to reduce the isolated areas and to obtain a complete and detailed image. A sufficient number of photogrammetric landmarks (GCP - Ground Control Point) is required to make geographical references of the images processed within the point cloud adjustment; the number of GCPs varies depending on the size of the investigated area and its complexity. The accuracy of the obtained point cloud is usually very high (up to a few centimeters), and these data can thus be used for further analysis and for extracting the features from the investigated area (Rusnák et al, 2017).

Currently, many photogrammetric mapping methods have used drones to retrieve and record data and phenomena on the Earth's surface (Maza et al, 2011). This is because the use of a drone equipped with GNSS system (Global Navigation Satellite System) and IMU system (Inertial Measurement Unit) for air measurements is very efficient and cheaper as compared to chartering a plane, it 
also allows flying over difficult areas. accessible and significantly reduces the execution time of the work (Zhang and Kovacs, 2012).

The idea of developing a technical work scheme that integrates modern, precision means and technologies for analyzing agricultural surfaces and especially those used as pastures and meadows, is based on several practical considerations: the large size and complexity of the investigated space, the need for the rapid acquisition of pratological data, problems related to the accessibility of the territory, etc.

For a complete and complex analysis of the information, the processing of the results can be done later in Geographic Information Systems (Simon et al, 2019).

In this context, the purpose of the research is to develop a study model in the pastoral environment that integrates the UAV technology and the GIS applications, the results obtained having both practical and methodological character.

\section{MATERIALS AND METHODS}

\subsection{Testing areas of the study model}

In order to test the applicability of UAV technology in the pastoral space through the proposed working model, six areas (grassland surfaces) were selected and flown in Arad, Suceava, Caras-Severin, Hunedoara and Timis counties (fig. 1).
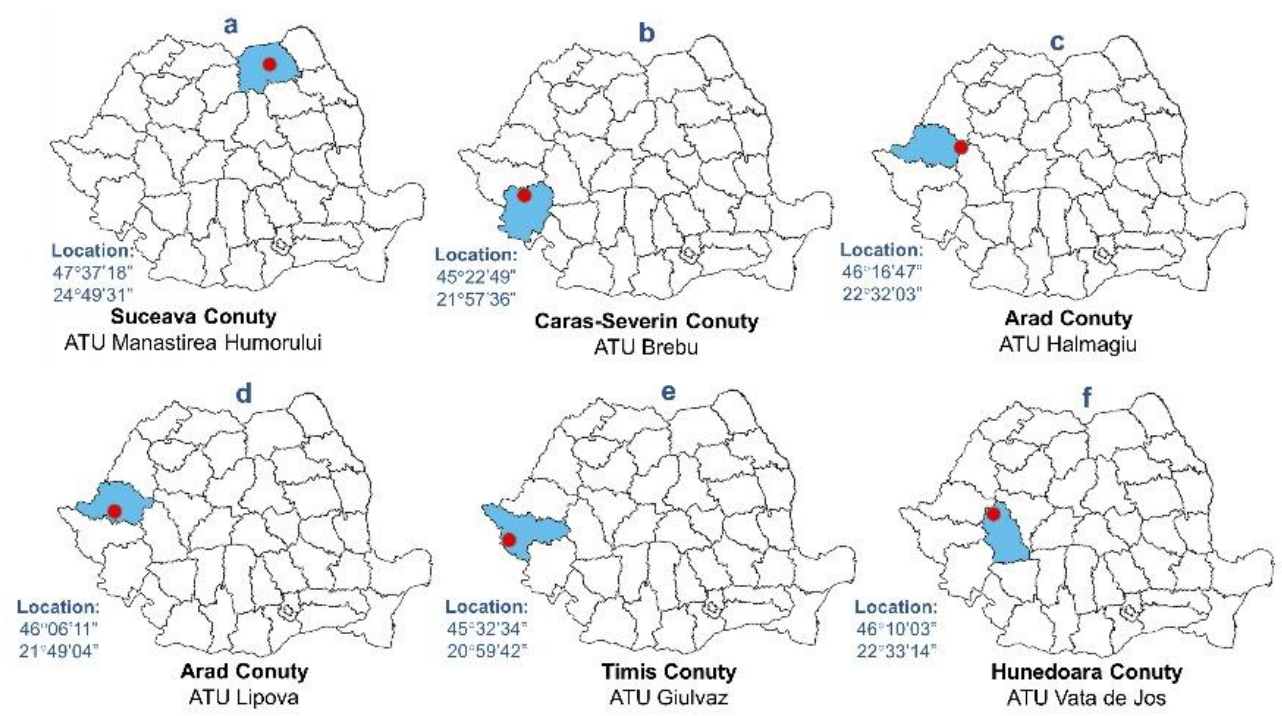

Figure 1. Test areas with UAV equipment (processing after www.geospatial.org) 


\subsection{Research methodology}

The stages of the research methodology are presented schematically in fig 2 .

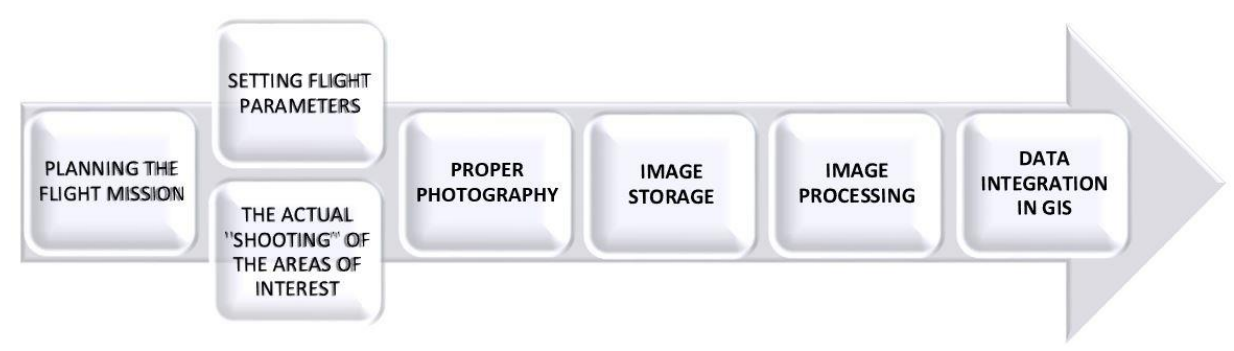

Figure 2. Research methodology

\subsection{Technical equipment used}

The field stage:

- DJI Phantom 4 Pro drone - data obtained with DJI GO on manual flights and Pix4Dcapture on automatic flights;

- Leica Geosystems GNSS equipment, the GS08 Plus model - for determining the coordinates of the ground control points located on the investigated areas - data obtained with the Leica SmartWorx application.

The office stage:

- Leica Infinity, for processing the observations obtained with the GNSS equipment;

- Agisoft PhotoScan Professional or Pix4Dmapper for aerial image processing;

- Global Mapper and Leica Cyclone for "modeling" the results obtained;

- Autodesk AutoCAD and ArcGIS for extracting the necessary information and integrating the results in the CAD environment, respectively GIS.

\section{RESULTS AND DISCUSSIONS}

In the last years, the automation, in all the theoretical and practical fields, is transposed through the high level of autonomous photogrammetric processing. One of the most important advantages of UAV systems is the ability to quickly provide high temporal and spatial resolution information, but also to enable rapid response in required situations (Simon et al, 2018; Raparelli and Bajocco, 2019). Another major advantage is that drones can be used in risky situations, inaccessible areas or with some political, military, social, etc. limitations (Wall and Monahan, 2011).

As the vast majority of the grassland surfaces in Romania are arranged in hill and mountain areas, which are difficult to reach, UAV techniques can facilitate the 
identification and monitoring of remote grassland surfaces. In this context, we propose to go through several stages.

\subsection{Flight mission planning and proper photography}

In the first phase, a terrain reconnaissance is carried out and the flight plan is established together with the ground control points. The flight plan depending on the size and complexity of the investigated area and can be made using the Pix4Dcapture application so that the entire area is flown over from a single flight or a manual flight can be made through the DJI GO application. In the case of automatic flight, in the Pix4Dcapture application, the route to be followed by the drone together with the flight parameters, the height at which it will be performed, the degree of image overlap, etc. is established. If we do not use an established flight plan, all these parameters are set in real time during the flight from the DJI GO application.

The planning of GNSS determinations involves, in the first phase, establishing the approximate position of the points that will serve as photogrammetric landmarks and then of the working mode, of the sessions for realizing the observations and the stationary times. These photogrammetric landmarks whose coordinates were determined in the national Stereographic 1970 projection system realize the connection between terrain and image (fig. 3 ).

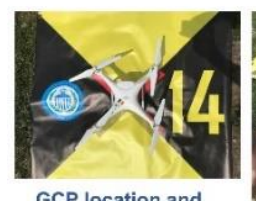

GCP location and GNSS determination
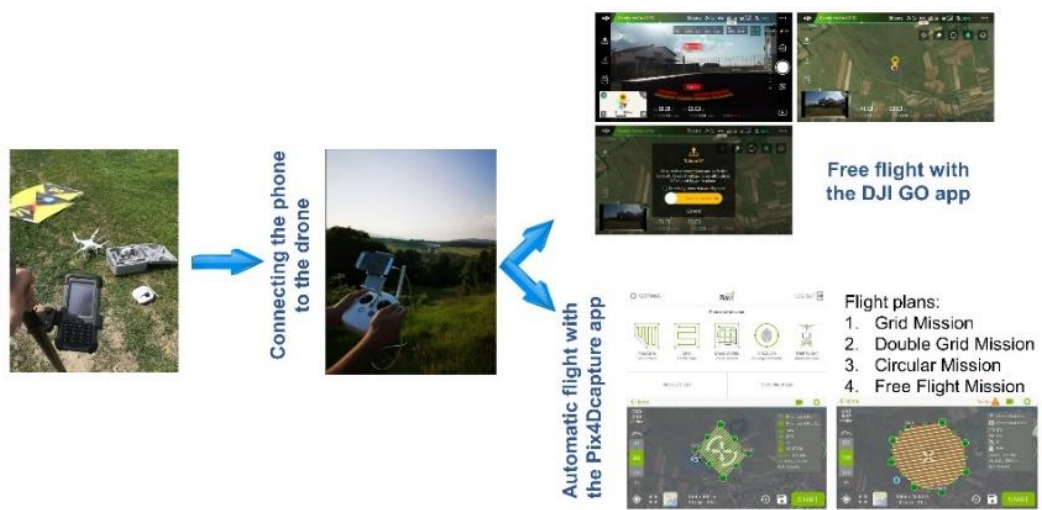

Figure 3. Flight mission planning

Because the battery life is about 20-25 minutes depending on the weather conditions, the route is set in such a way that it respects this time. In the event of battery depletion, the device has the ability to return to the take-off point. After replacing the battery, the drone will continue its mission exactly from where it 
remained. Their own research has shown that as a flight with a battery can cover up to 40 hectares. The possibility of successive use of several accumulators allows the overgrowth of large areas of grasslands, of the order of hundreds of hectares, which, in other situations, could be crossed in a long time and with considerable effort.

Most of the missions realized through the Pix4Dcapture application were performed by simple grid flights in polygonal form with an image overlap of $80 \%$ transversal and $70 \%$ longitudinally, the camera angle was set to $90^{\circ}$, and the flight altitude was set at 100-120 meters (fig. 4).

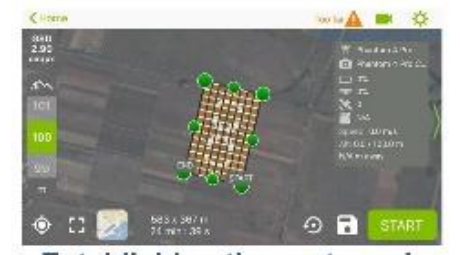

Establishing the route and flight height

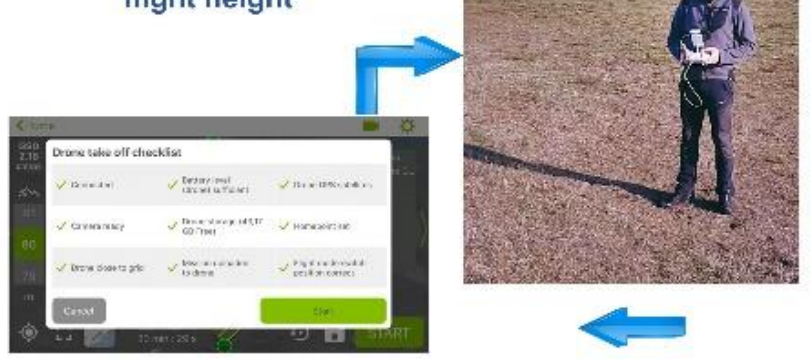

Complete the cheklist

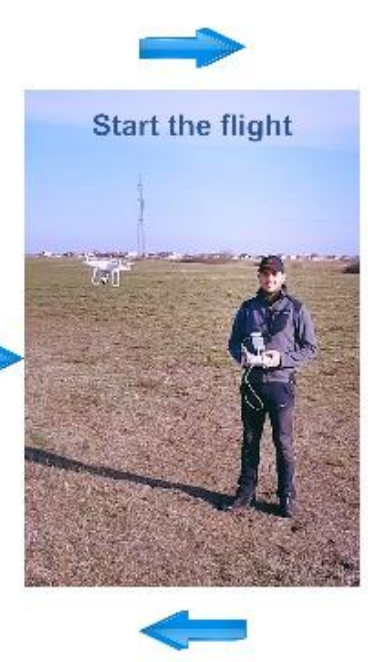

connected

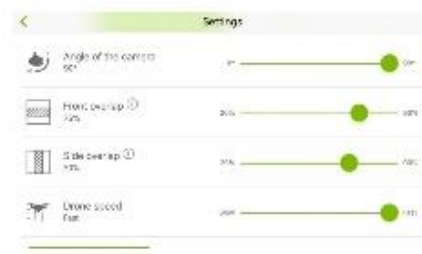

Setting camera parameters

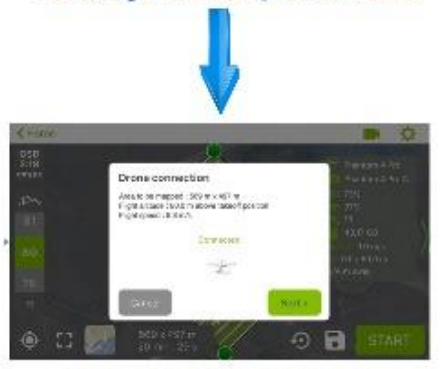

Verify that the drone is

Figure 4. Setting the flight parameters

In the case of areas flown by DJI GO, decisions related to altitude, speed of movement or angle of the room are made in real time, depending on the details we want to highlight. Manual flights are recommended for panoramic images, but previous research (Simon et al, 2018) has shown that automatic flight is recommended to obtain a quality $3 \mathrm{D}$ point cloud and orthophoto. In the case of small surfaces, this can also be done by manual flight.

In the case of automatic flights, the images are captured automatically depending on the degree of overlap established, whereas in the case of the manual flights, the images are captured classically by pressing the camera button in the application (fig. 5). 


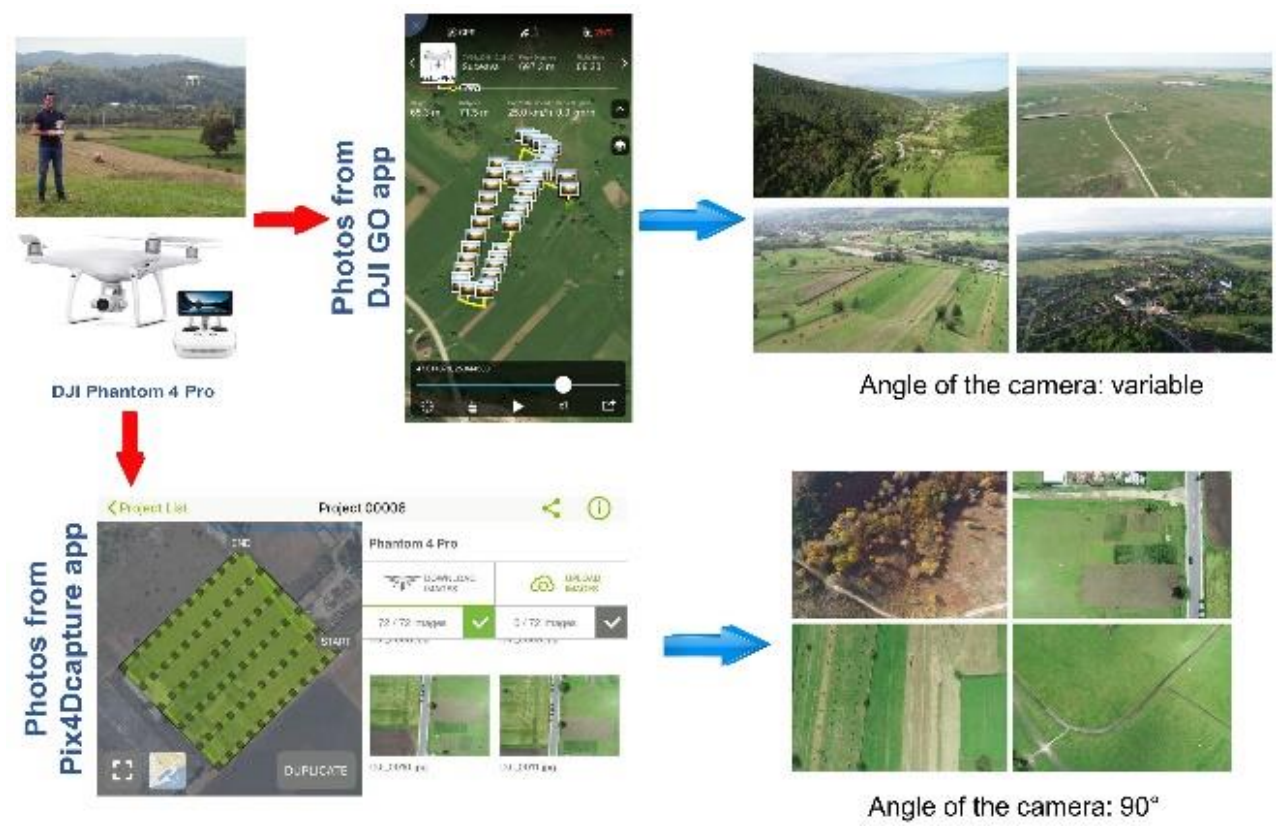

Figure 5. Capture images

\subsection{Image storage}

Images were stored on the Micro SD memory card and downloaded, either through a card reader on a laptop or computer or directly into a Cloud account from which we can download them later (fig. 6).

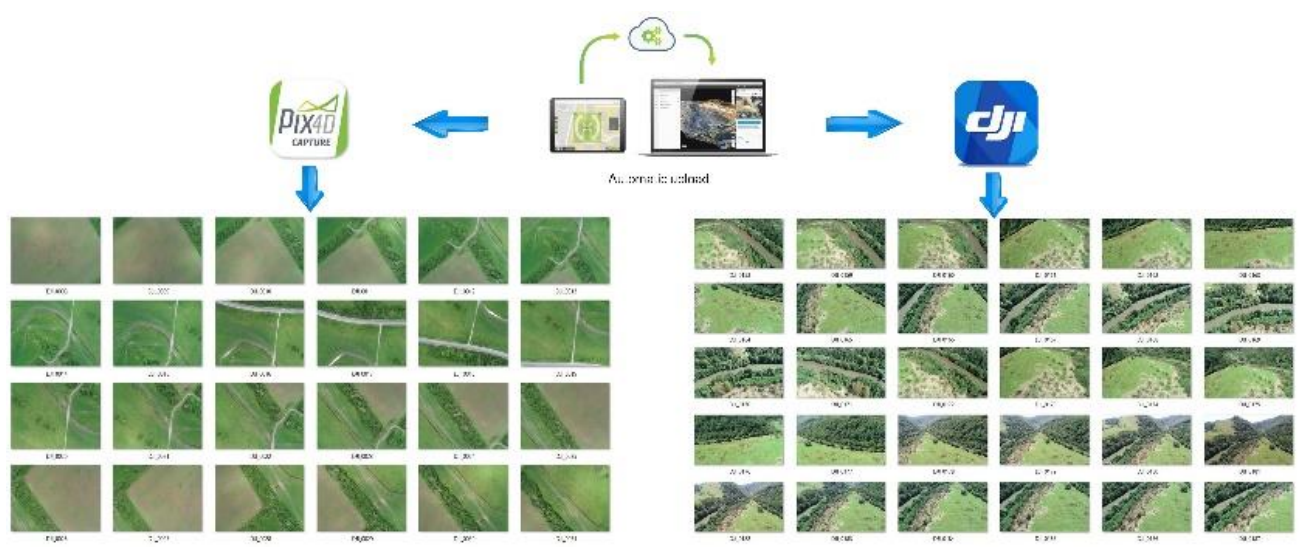

Figure 6. Download images 


\subsection{Image processing}

In the present study, in most cases, image processing was performed with Agisoft PhotoScan Professional software and with Pix4Dmapper software for several areas. Processing involves determining the flight path of the drone. Stereoscopic view allows viewing of an object from two different perspectives, such as aerial photography taken from different camera positions.

The result of mapping the data using the drone can produce very high resolution images, it also produces a three-dimensional image of the recorded surface. Photo alignment is done to identify the points in each photo and to make the same matching process in two or more photos (fig. 7).

In the case of a complete workflow based on the UAV technology together with the GNSS technology, we can safely say that although the automation has reached a high level of performance for the automatic extraction of the connection points and the generation of the Digital Elevation Model, a high percentage of time is absorbed by the acquisition of images and measurements of photogrammetric landmarks, especially if direct georeferencing cannot be performed.

Francesco Nex and Fabio Remondino (2014) estimated that the time required for feature extraction depends on their typology; most of the time being devoted to the acquisition of images (20\%) and their processing to obtain the Digital Surface Model (25\%).

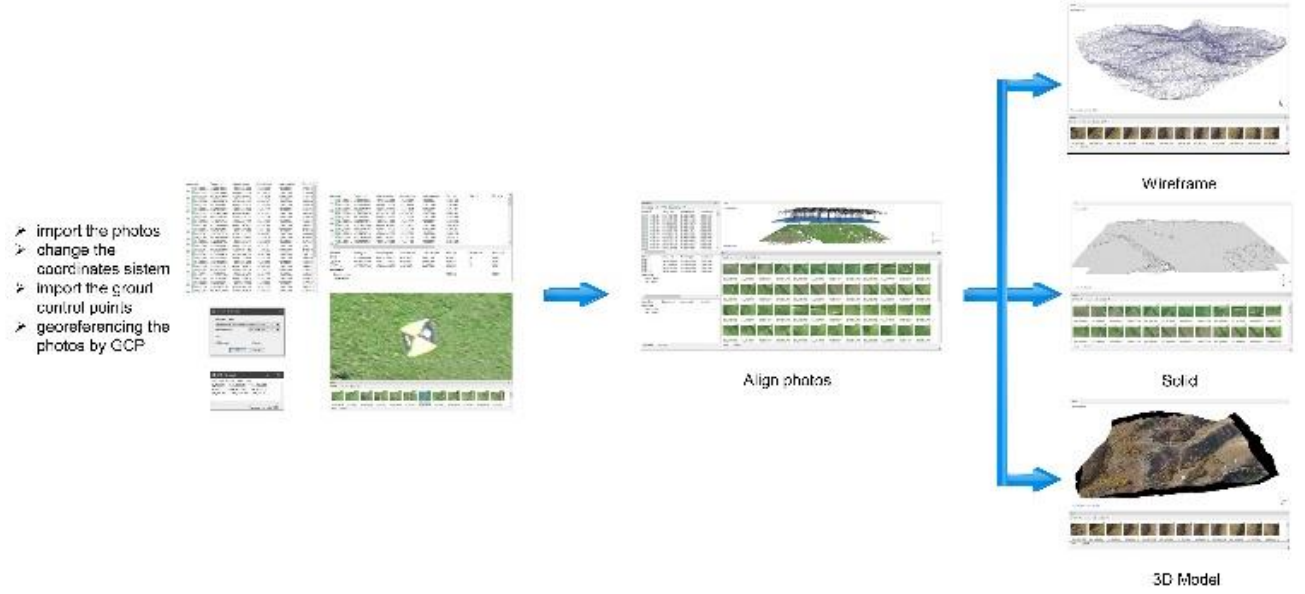

Figure 7. Image processing

After completing the processing, Agisoft Photoscan Professional or Pix4Dmapper software allows us to view quality reports of the results and to export these results obtained in different extensions compatible with other applications or programs that we will use to extract the necessary information. 


\subsection{Data integration in GIS}

An efficient and highly complex way to use data acquired with UAV equipment is to integrate it into the GIS environment (Capolupo et al, 2015; Cohen et al, 2018; Herrmann et al, 2020; Mahajan and Bundel, 2017; Simon et al, 2018 ). In this environment, numerous products can be obtained, useful in both quantitative and qualitative analysis of the pastoral area (table 1).

Table 1. Data integration in GIS

\begin{tabular}{|l|l|}
\hline \multicolumn{1}{|c|}{ UAV product } & \multicolumn{1}{c|}{ GIS product } \\
\hline \multirow{4}{*}{ Point clouds } & Digital Elevation Model \\
\hline & Relief maps \\
\hline & Climate maps \\
\hline & 3D modeling \\
\hline & Hydrological analysis \\
\hline & Volumetric calculations \\
\hline \multirow{4}{*}{ Orthophotomap } & Assisted classification \\
\hline & Analysis of changes \\
\hline & Topo-cadastal measurements \\
\hline & Identification of objectives \\
\hline & Surface monitoring \\
\hline
\end{tabular}

The integration of the data obtained in the GIS allows the complex analysis, together with other geospatial data sets.

The images and products obtained by UAV equipment can be used both in the GIS environment, but also in the CAD environment, with numerous applications in agriculture, forestry, spatial planning, urbanism and architecture, topography and cadastre or any activity area that uses geospatial data.

\section{CONCLUSIONS}

By using the UAV equipment, based on the model designed, we obtain topocadastral information, pratological information or information useful in territorial planning, with high accuracy and spatial location, represented cartographically.

Compared with the classical research methods, the use of the working model applicable in the pastoral space, based on geomatic technologies, has the effect of reducing the working time and the number of operators, the possibility of tracking in time and space of the investigated territory, but also the formation of certain bases graphic and descriptive data used to generate cartographic materials, with possibilities for use in other subsequent projects.

The working model applied in the analysis of the pastoral space, technically complex, comprises a logical succession of stages that also have individual results 
(from each stage can be extracted geospatial products), and the final products can be used in various ways, both in pastoral space, as well as in other segments of the geographical environment.

The UAV technology can study areas with relatively large grassland areas, found in difficult environmental conditions, in adverse weather conditions.

\section{Bibliography}

Capolupo, A., Kooistra, L., Berendonk, C., Boccia, L., Suomalainen, J., (2015), Estimating Plant Traits of Grasslands from UAV-Acquired Hyperspectral Images, A Comparison of Statistical Approaches. ISPRS Int. J. Geo-Inf. 2015, 4, 2792-2820, https://doi.org/10.3390/ijgi4042792

Casian, A., Șmuleac, A., Simon, M., (2019), Possibilities of using the UAV photogrammetry in the realization of the topo-cadastral documentation, Research Journal of Agricultural Science, 51(2), pp. 96-106

Cohen, O., Cartier, A., Ruz, M.H., (2018), Mapping Coastal Dunes Morphology and Habitats Evolution Using UAV and Ultra-High Spatial Resolution Photogrammetry, International Workshop 'Management of Coastal Dunes and Sandy Beaches. Dunkirk, [link]

Cojocariu, Luminiţa, Bordean, Despina-Maria, Copacean, Loredana, Hoancea, Lia, (2018), Evaluation of the biodiversity protection degree in Romanian Banat by geomatic methods, SGEM 2018, Section Ecology and Environmental Protection, Conference proceedings, vol.18, issue 5.1. pp 369-376, https://doiorg/10.5593/sgem.2018/5.1

Ezequiel, C.A.F., Cua, M., Libatique, N.C., (2014), UAV Aerial Imaging Applications for Post-Disaster Assessment Environmental Management and Infrastructure Development. In Proceedings of the International Conference on Unmanned Aerial Systems, pp. 274-283, Orlando, FL, USA, DOI: 10.1109/ICUAS.2014.6842266

Herrmann, I., Bdolach, E., Montekyo, Y. et al., (2020), Assessment of maize yield and phenology by drone-mounted superspectral camera, Precision Agric 21, 51-76. https://doi.org/10.1007/s11119-019-09659-5

Kyriacos, T., (2017), The use of UAVs for monitoring land degradation, Proc. SPIE 10428 , Earth Resources and Environmental Remote Sensing/GIS Applications VIII, 104280E; https://doi.org/10.1117/12.2279512

Mahajan, U., Bundel, B.R., (2017), Drones for Normalized Difference Vegetation Index (NDVI), to Estimate Crop Health for Precision Agriculture: A Cheaper Alternative for Spatial Satellite Sensors, International Conference on Innovative Research in Agriculture, Food Science, Forestry, Horticulture, Aquaculture, Animal Sciences, Biodiversity, Ecological Sciences and Climate Change (AFHABEC-2016). At Jawaharlal Nehru University, New Delhi, India, [link]

Maza, I., Caballero, F., Capitán, J., Martínez-De-Dios, J.R., Ollero, A., (2011), Experimental results in multi-UAV coordination for disaster management and civil 
security applications. J. Intell. Robot. Syst. Theory Appl. 2011, 61, 563-585, DOI: https://doi.org/10.1007/s10846-010-9497-5

Nex, F., Remondino, F., (2014), UAV for 3D mapping applications: a review. Appl Geomat 6, 1-15. https://doi.org/10.1007/s12518-013-0120-x

Raparelli, Elisabetta, Bajocco, Sofia, (2019), A bibliometric analysis on the use of unmanned aerial vehicles in agricultural and forestry studies, International Journal of Remote Sensing, 40:24, 9070-9083, DOI: https://doi.org/10.1080/01431161.2019.1569793

Remondino, F., Barazzetti, L., Nex, F., Scaioni, M., Sarazzi, D., (2011), UAV Photogrammetry for Mapping and 3D Modeling-Current Status and Future Perspectives. Int. Arch. Photogramm. Remote Sens. Spat. Inf. Sci. 2011, XXXVIII, 14-16, [link]

Rusnák, M., Sládek, J., Kidova, Anna, Lehotský, M., (2017), Template for highresolution river landscape mapping using UAV technology. Measurement. 115. 10.1016/j.measurement.2017.10.023,

https://doi.org/10.1016/j.measurement.2017.10.023

Samad, A.M., Kamarulzaman, N., Hamdani, M.A., Mastor, T.A., Hashim, K.A., (2013), The potential of Unmanned Aerial Vehicle (UAV) for civilian and mapping application. In Proceedings of the IEEE 3rd International Conference on System Engineering and Technology (ICSET), pp. 313-318, Shah Alam, Malaysia, DOI: 10.1109/ICSEngT.2013.6650191

Sanches, G., Duft, G.D., Kölln, O.T., Dos Santos Luciano, A.C., Quassi De Castro, S.G., Okuno, F.M., Junqueira Franco, H.C., (2018), The Potential for RGB Images Obtained Using Unmanned Aerial Vehicle to Assess and Predict Yield in Sugarcane Fields, International Journal of Remote Sensing 39 (15-16): 5402-5414. doi: https://doi.org/10.1080/01431161.2018.1448484

Simon, M., Copăcean, Loredana, Cojocariu, Luminiţa, (2018), UAV technology for the detection of spatio-temporal changes of the useful area for forage of grassland, Research Journal of Agricultural Science, 50 (4), 2018, pp. 332-341, [link]

Simon, M., Copăcean, Loredana, Cojocariu, Luminiţa, (2019), Viewing data sets produced by photogrammetry in web browsers. applications on grasslands in Arad county, Research Journal of Agricultural Science, 51 (3), pp. 133-142, [link]

Sona, G., Passonia, D., Pinto, L., Pagliari, D., Masseroni, D., Ortuani, B., Facchi, A., (2016), UAV Multispectral Survey to Map Soil and Crop for Precision Farming Applications, The International Archives of the Photogrammetry, Remote Sensing and Spatial Information Sciences, Vols. XLI-B1, pp. 1023-1029, https://doi.org/10.5194/isprs-archives-XLI-B1-1023-2016

Sun, Y., Yi, S., Hou, F., (2018), Unmanned aerial vehicle methods makes species composition monitoring easier in grasslands. Ecol. Indic. 2018,95, 825-830, https://doi.org/10.1016/j.ecolind.2018.08.042

Wall, T., Monahan, T., (2011), Surveillance and violence from afar: The politics of drones and liminal security-scapes. Theoretical Criminology. 15. 239-254. https://doi.org/10.1177/1362480610396650. 
Zhang, C., Kovacs, J.M., (2012), The application of small unmanned aerial systems for precision agriculture: A review. Precis. Agric., 13, 693-712

...http://www.geo-spatial.org/download/romania-seturi-vectoriale accessed in 04.07.2919

...User Manual DJI GO - https://store.dji.com/guides/dji-go-4-manual/

...User Manual Pix4Dcapture - https://support.pix4d.com/hc/en-us/sections/200733429Getting-Started-User-Manuals-Special-Install

...Agisoft PhotoScan User Manual Professional Edition, Version 1.4, https://www.agisoft.com/pdf/photoscan-pro_1_4_en.pdf

...Leica Cyclone Model Documentation - https://leica-geosystems.com/products/laserscanners/software/leica-cyclone/leica-cyclone-model

-.. Leica Infinity Survey Software - https://leica-geosystems.com/products/gnsssystems/software/leica-infinity

•..Leica SmartWorx Viva Field Software - https://leica-geosystems.com/products/totalstations/software/leica-smartworx-viva

...ArcMap Documentation - https://desktop.arcgis.com/en/arcmap/

(C) 2020 by the authors. Licensee UAIC, Iasi, Romania. This article is an open access article distributed under the terms and conditions of the Creative Commons Attribution (CC BY-NC-ND) license (https://creativecommons.org/licenses/by-nc-nd/4.0). 